\title{
A placental dilemma: exaggerated placental site tumour
}

\section{Niranjana Jayakrishnan*, Krishnapillai Jayakrishnan}

Department of Obstetrics and Gynaecology, KJK hospital, Shawallace Lane, Nalanchira ,Trivandrum, Kerala, India

Received: 25 April 2016

Revised: 08 June 2016

Accepted: 09 June 2016

\section{*Correspondence:}

Dr. Niranjana Jayakrishnan,

E-mail: niranjana_jk@ hotmail.com

Copyright: (c) the author(s), publisher and licensee Medip Academy. This is an open-access article distributed under the terms of the Creative Commons Attribution Non-Commercial License, which permits unrestricted non-commercial use, distribution, and reproduction in any medium, provided the original work is properly cited.

\begin{abstract}
Exaggerated placental site is defined as a non-neoplastic lesion characterized with infiltration of extravilleous intermediate trophoblasts into the myometrium and the walls of blood vessels of the normal placental implantation area. They are commonly seen following spontaneous or elective abortions and present rarely as a cause of third stage bleeding or post-partum hemorrhage. A case of an exaggerated placental site is presented in this article. It is aimed to review the current information about this rare condition. We encountered a case of exaggerated placental site (EPS) reaction following evacuation of a missed abortion in a 34 year old lady. She presented to us, with bleeding per vaginum, not responding to medical management. Hysteroscopy was done and a fleshy mass noted in the posterior wall was resected and sent for examination. Histopathological report was an exaggerated placental site. EPS is a type of trophoblastic lesion and can cause worry to the surgeon at a first glance. Its clinical course has been reported by few. Its diagnosis is mainly by ultrasound and histopathology.
\end{abstract}

Keywords: Exaggerated placental site, Intermediate trophoblast, Term pregnancy, Postpartum hemorrhage

\section{INTRODUCTION}

Exaggerated placental site (EPS) reaction is an exuberant physiologic process in which intermediate trophoblasts infiltrate the underlying endometrium and myometrium at the implantation site. These lesions may occur following normal pregnancy, ectopic pregnancy, aborts or molar pregnancy. They are seen in $1.6 \%$ of the first trimester abort uses. This lesion was formerly defined as syncytial endometritis, but this is neither an inflammatory process nor it is limited within the endometrium. Therefore the term 'exaggerated placental site' has been recommended by theWHO.'

The histopathological examination revealed an exuberant proliferation of trophoblastic cells in the placental site, a low Ki-67 labelling index and the absence of mitotic activity. Distinguishing EPS reaction from the other intermediate trophoblastic tumours is critical, as the latter may likely involve surgical intervention and/or chemotherapy, although no specific treatment and followup is required for EPS reaction. It is necessary to be aware of this pathology and take biopsies from suspicious lesions in the placental site for pathologic examination. ${ }^{2}$

\section{CASE REPORT}

A 34 year old female patient, P1L1A1, Previous LSCS 9 years back and an abortion in December 2013 for which D and E done, presented to our hospital in February 2014, with complaints of bleeding per vaginum since 2 months. Bleeding was minimal in nature, changing around 1-2 pads/day. She had undergone four D and E's for the same complaint elsewhere and was told that she had molar changes inside the uterus, no reports available.

On examination, patient had mild pallor. A brownish discharge seen on per speculum examination with a bulky uterus on per vaginal examination. On transvaginal ultrasonography, the endometrium was thick $(\sim 19 \mathrm{~mm})$. 
An anechoic area with fluid collection of $9 \mathrm{~mm}$ ? Gestational sac seen in the fundal region. Doppler revealed increased vascularity in an area of $2 \times 2 \mathrm{~cm}$ surrounding the sac. Blood investigations showed beta hcg-6 mIU/ml.

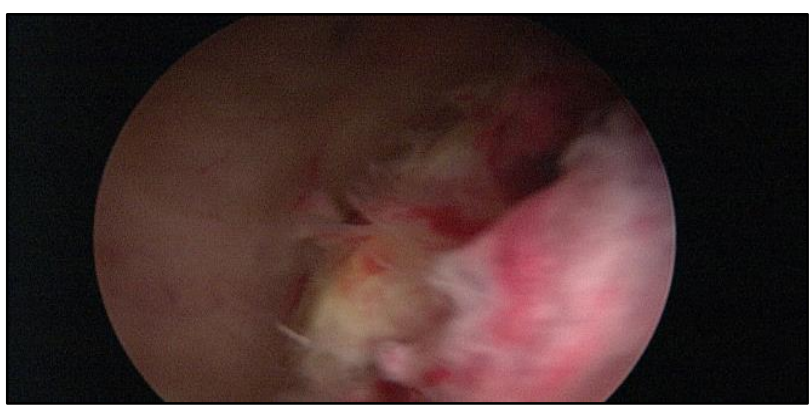

Figure 1: Hysteroscopic: the fleshy mass seen on the posterior wall.

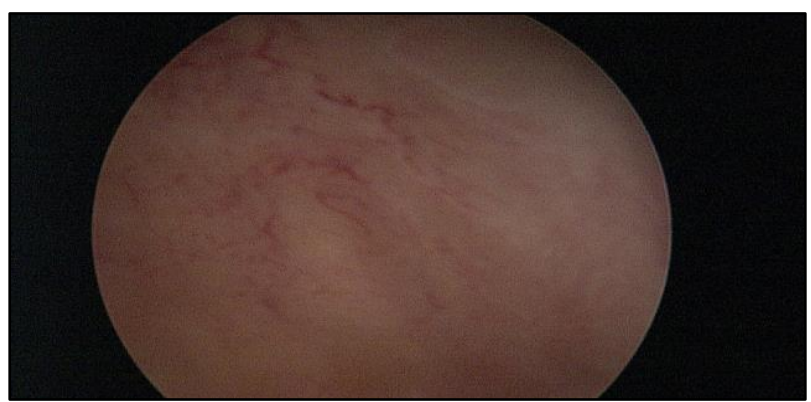

Figure 2: Hysteroscopic: increased vascularity seen over the fundus.

Since the ultrasound features were not typical of molar changes, she was subjected to an operative hysteroscopy, after arranging blood. Hysteroscopy was carried out. Using a 26 Fr resectoscope, a yellowish white tissue mass seen in the posterior wall, was resected, with wire loop, using bipolar current and sent for histopathological examination (Figure 1 and 2). Post procedure, patient was asymptomatic. She developed minimal bleeding on post op day 5, managed with progestogens. Repeat TVS on day 10 , showed increased vascularity over the anterior and posterior myometrium suggestive of adenomyosis. No intra uterine mass seen.
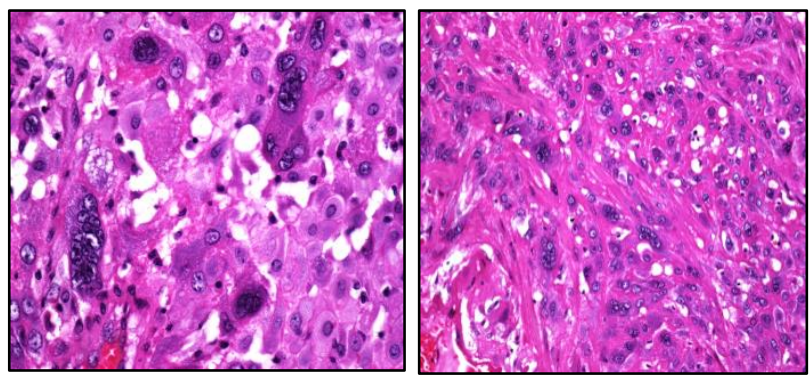

Figure 3: High power view of numerous multinucleated intermediate trophoblastic cells suggestive of exaggerated placental site reaction.
Histopathology revealed adenomyotic fragments of myometrium and haemorrhagic material, with very few degenerated villi and decidual cells (Figure 3). Multi nucleated trophoblastic cells were seen scattered in between myometrial fibres. This was suggestive of an exaggerated placental site reaction.

\section{DISCUSSION}

The infiltration of the endometrium and myometrium at the implantation site by intermediate trophoblastic cells is termed Exaggerated Placental Site. It is a rare and a benign condition and the diagnosis is mainly histopathological proliferations of the intermediate trophoblast are also the placental site nodule or plaque and the placental site trophoblastic tumor. ${ }^{3}$ These are too considered as the differential diagnosis

Rarely seen in normal pregnancy, exaggerated placental site is the invasion of intermediate trophoblasts and synctiotrophoblasts into the endometrium, myometrium and blood vessels of the uterine wall. It is commonly seen in aborts material and can cause post-partum hemorrhage. ${ }^{4}$ The intermediate trophoblasts functions as an anchoring device, holding the placenta to the maternal tissue to maintain the pregnancy, but its role post-partum is unclear.

Its diagnosis is mainly pathological.

The immunohistochemical markers are confirmatory. The ki-67 labeling index is zero in EPS where as in placental site trophoblastic tumour; it is more than $10 \%$. Absence of mitosis is another characteristic feature of exaggerated placental site reaction. Chorionic villi are usually present. $^{5}$

\section{CONCLUSION}

EPS is a condition, not consistent with molar and gestational trophoblastic neoplastic. It regresses following a thorough curettage. It is distinguished by its immunohistochemistry and morphological appearance.

No specific treatment or follow-up is necessary.

It should be considered, though rare, as a differential diagnosis of heavy bleeding after a delivery or a miscarriage.

Funding: No funding sources

Conflict of interest: None declared

Ethical approval: Not required

\section{REFERENCES}

1. Shih IM, Kurman RJ. The pathology of intermediate trophoblastic tumors and tumor-like lesions. Int $\mathrm{J}$ Gynecol Pathol. 2001;20(1):31-47. 
2. Akbayir O, Alkis I, Corbacioglu A, Ekiz A, Akca A, Cekic S. Exaggerated placental site reaction detected during caesarean delivery: a case report. Clin Exp Obstet Gynecol. 2012;39(2):234-5.

3. Horn LC, Einenkel J, Vogel M. Histopathology of gestational trophoblastic disease. An update. Pathologe. 2009;30(4):313-23.
4. Liu G, Yuan B, Wang Y. Exaggerated placental site leading to postpartum hemorrhage: a case report. J Reprod Med. 2013;58(9-10):448-50.

5. Erdogan NY, Kara M. Exaggerated placental site with term pregnancy. Pak J Med Sci. 2012;28(5):977-8.

Cite this article as: Jayakrishnan N, Jayakrishnan K. A placental dilemma: exaggerated placental site tumour. Int J Reprod Contracept Obstet Gynecol 2016;5:2425-7. 